Original Research Article

\title{
Cost comparisons of seven leading brands of the Hypolipidemic drug, Rosuvastatin available in an India city
}

\author{
Vikram A. Rajadnya*, Archana G. Dhavalshankh
}

Department of Pharmacology, D.Y. Patil Medical College, Kolhapur, Maharashtra, India

Received: 24 May 2019

Accepted: 10 June 2019

\section{*Correspondence to:}

Dr. Vikram A. Rajadnya,

Email: sportsdocind@ rediffmail.com

Copyright: (C) the author(s), publisher and licensee Medip Academy. This is an openaccess article distributed under the terms of the Creative Commons Attribution NonCommercial License, which permits unrestricted noncommercial use, distribution, and reproduction in any medium, provided the original work is properly cited.

\begin{abstract}
Background: Hypolipidemic drugs need to be prescribed lifelong for most of the selected patients, once started. Price variation can lead to huge financial strain on the patients, especially when cost associated issues are not considered by the prescribing medical practitioner. This study was conducted to compare the cost, to the patient, of seven most commonly prescribed preparations of different brands of Rosuvastatin ten milligram, in Kolhapur city.

Methods: Authors purchased a strip of 10 capsules each of the seven leading brands of Rosuvastatin ten milligrams. The prices of the strip of 10 capsules of each of the seven chosen brands were compared. Finally, the cost of each of these seven brands for one year, was compared directly as well as using percentages. The data was collected, analysed and presented in tabular forms and figures.

Results: The data of the cost of seven different brands of a single hypolipidemic drug, Rosuvastatin ten milligram shows that the cost of the costliest among the seven brands of this drug for one year is almost two times that of the cheapest brand, or in other words almost 200 percent that of the cheapest brand.

Conclusions: The cost differences between the cheapest and the costliest brands were substantial. The cost of remaining five brands was dispersed in between these two extremes. India, with a major part of the population being highly concerned about the cost of medications, the prescribing medical practitioner must select the preparation wisely. The most costly preparation of Rosuvastatin ten milligram can substantially add to the financial strain on the patient's yearly expenses. Thus, Pharmaco economic considerations must be a prime concern while making a decision to prescribe medicines, especially in a country like India.
\end{abstract}

Keywords: Cost per year, Hypolipidemic drugs, Pharmaco economics, Rosuvastatin ten milligram

\section{INTRODUCTION}

Dyslipidemia is a major cause of atherosclerosis and thus of certain major Chronic Non Communicable Diseases (NCD ) such as ischemic heart disease and stroke. ${ }^{1}$ Use of hypolipidemic drugs is a very important part of the treatment prescribed to such patients, statins are one very important group of hypolipidemic drugs. ${ }^{2}$ Rosuvastatin being one such very important drug belonging to statin group. These drugs act by inhibiting HMG COA enzyme in the liver Many brand preparations of Rosuvastatin are available in India. ${ }^{3}$ This fact is associated with another fact that majority of the preparations are associated with a great price disparity. As hypolipidemic drugs are to be taken lifelong, in almost all of such patients, even a small price rise results in a large financial strain on patients particularly those in lower socioeconomic status, of the developing countries. In India, medical insurance is not so widely established amongst the populations. Major part of healthcare expenditure is paid by the patient or the end 
user. In 1997 NPPA (National Pharmaceutical Pricing Authority) was established for ensuring availability and affordability of the drugs. The drug price control order (DPCO) 2013 is one such effort under NPPA. DPCO was established by the government with the aim of cutting down the cost of essential medicines. ${ }^{4}$ This study was undertaken to evaluate the cost differences in seven preparations of different brands of the hypolipidemic drug, of the statin, i.e. Rosuvastatin ten milligram.

\section{METHODS}

Authors purchased strips of 10 capsules each of seven leading, different brands of Rosuvastatin ten milligram from the local market of an Indian city of Kolhapur. The price paid was the M.R.P. (Maximum Retail Price). All the seven strips were recently manufactured, within last three months. The seven different brand strips were labeled as A, B, C, D and E, F, G under the coding, to maintain the confidentiality of those brands.

The price of the strips of 10 capsules of each brand were recorded under their specific code name. This price was converted to the cost per year of each brand preparation for a single patient, based on one capsule a day dosing schedule. This data was analyzed and presented in the form of tables, figures, bar diagrams for better visualization .

\section{Inclusion and exclusion criteria}

Only those branded preparations were included in the study which were most commonly sold in the local market of Kolhapur city, at the time of the study. All of the included drugs were available for oral intake. Preparations containing only Rosuvastatin ten milligram were selected. fixed dose combinations were not included.

\section{RESULTS}

The strips of 10 capsules each of the most leading seven brands of Rosuvastatin ten mg were purchased from local shops in Kolhapur city. The cost of a single capsule, cost per year to the patient in rupees were calculated, for each brand. Thus the costliest brand, i.e. Brand $\mathrm{G}$ costs almost two times more than the cheapest brand i.e. Brand A.

The costs of all other brands remain in between these two brands. The costs of each of the seven brands were also compared in percentages, where the cheapest brand (Brand A) cost was considered 100 percent.

Thus it can be seen that compared with the cheapest brand, the costliest brand (Brand G) costs 196 percent. The remaining five brands cost 106 percent, 113 percent and 135 percent, 150 percent, 178 percent for brands, F, D and $\mathrm{B}, \mathrm{C}$ and $\mathrm{E}$, respectively. The data was presented in the form of tables and figures.

Table 1 shows, the prices for 10 capsules as well as single capsule of each of the seven brand preparations under the specified code names. Thus, it can be seen that the brand A provides the drug Rosuvastatin ten milligram, the cheapest, costing 86 rupees for 10 capsules, while costing 8.6 rupees for a single capsule. In contrast brand $G$ is the costliest among all seven, costing 169.9 rupees for 10 capsules and 16.89 rupees for single capsule. The costs of the remaining five brands, lie in between.

Table 1 : Prices of a strip of 10 capsules of seven different brands of Rosuvastatin ten milligram.

\begin{tabular}{|lll|}
\hline Brand code & $\begin{array}{l}\text { Price for } \mathbf{1 0} \text { tab. } \\
\text { (rupee) }\end{array}$ & $\begin{array}{l}\text { Price of } \mathbf{1} \text { tab. } \\
\text { (rupees) }\end{array}$ \\
\hline A. & 86 & 8.6 \\
\hline B. & 115.8 & 11.58 \\
\hline C. & 129 & 12.9 \\
\hline D. & 96.83 & 9.68 \\
\hline E. & 153.33 & 15.33 \\
\hline F & 91 & 9.1 \\
\hline G & 169.9 & 16.89 \\
\hline
\end{tabular}

Table 2 represents the annual cost of each of the seven brand preparations, for a single patient, based on single capsule daily dosing. Thus, it can be observed that the cheapest, i.e. brand A costs 3139 rupees per year, for a single patient based on a single capsule daily basis, while the costliest brand, i.e. brand $\mathrm{G}$ costs 6165 rupees for a single patient based on single capsule daily dosing. The cost difference between the cheapest and the costliest brand is almost two times. Remaining five brands viz, B, C, D, E, F fall in between as far as the yearly cost is concerned

Table 2: Cost of seven brands of Rosuvastatin 10 milligram mg capsules per year to a single patient based on one capsule once daily dosing.

\begin{tabular}{|ll|}
\hline Brand & Annual cost (rupees) \\
\hline A. & 3139 \\
\hline B. & 4227 \\
\hline C. & 4708 \\
\hline D. & 3533 \\
\hline E. & 5595 \\
\hline F & 3322 \\
\hline G & 6165 \\
\hline
\end{tabular}

The calculations are based on a single daily dosing pattern. The figures are rounded off to the nearest number for simplicity

Table 3 presents the cost comparisons for a single patient, based on a single capsule daily basis of all the seven brands. This is presented in the form of percentages.

Thus, it can be seen that the brand A, the cheapest amongst all seven brands is considered to cost 100 percent. In this regard, the costliest brand, i.e. brand G, costs 196 percent as compared to brand A. Remaining five brands percent cost yearly fall between approximately 106 percent to 178 percent. 
Table 3: Comparison of cost of seven different brands of Rosuvastatin $10 \mathrm{mg}$ in percentage.

\begin{tabular}{|ll|}
\hline Brand & Comparative cost (percent) \\
\hline A. & 100 \\
\hline B. & 135 \\
\hline C. & 150 \\
\hline D. & 113 \\
\hline E. & 178 \\
\hline F & 106 \\
\hline G & 196 \\
\hline
\end{tabular}

The calculations are based on a single daily dosing pattern. The figures are rounded off to the nearest number for simplicity. The percent cost of the cheapest brand is considered 100 .

Figure 1 represents the annual cost of each of the seven brand preparations, for a single patient, based on single capsule daily dosing. Thus, it can be observed that the cheapest, i.e. brand A costs 3139 rupees per year, for a single patient based on a single capsule daily basis, while the costliest brand, i.e. brand $\mathrm{G}$ costs 6165 rupees for a single patient based on single capsule daily dosing.

The cost difference between the cheapest and the costliest brand is almost two times. Remaining five brands viz B, C, D, E, F fall in between as far as the yearly cost is concerned.

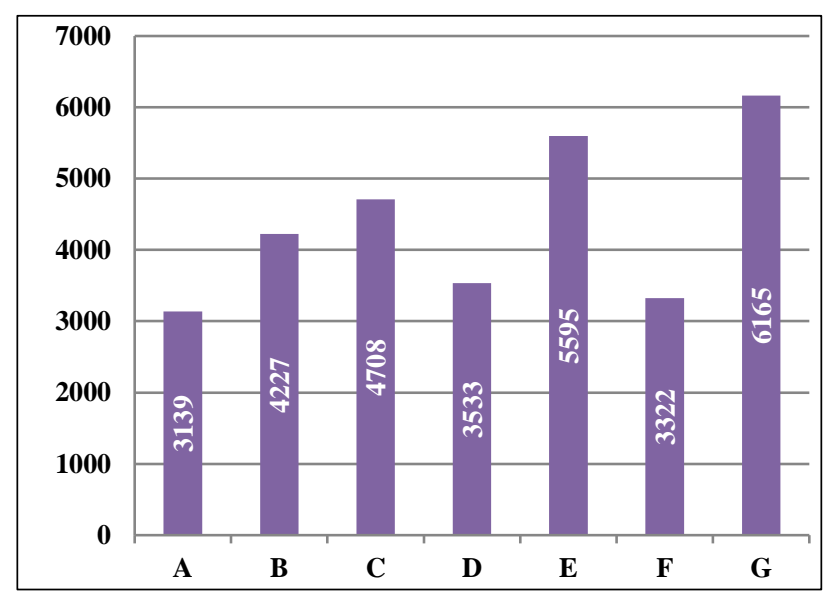

The calculations are based on a single tablet daily dosing pattern. The figures are rounded off to the nearest number for simplicity

\section{Figure 1: Cost per year of the seven different brand preparations of Rosuvastatin $\mathbf{1 0}$ milligram for a single patient.}

Figure 2 presents the cost comparisons for a single patient, based on a single capsule daily basis of all the seven brands. This is presented in the form of percentages.

Thus, it can be seen that the brand A, the cheapest amongst all seven brands is considered to cost 100 percent. In this regard, the costliest brand, i.e. brand G, costs 196 percent as compared to brand A. Remaining five brands percent cost yearly fall between approximately 106 percent to 178 percent.

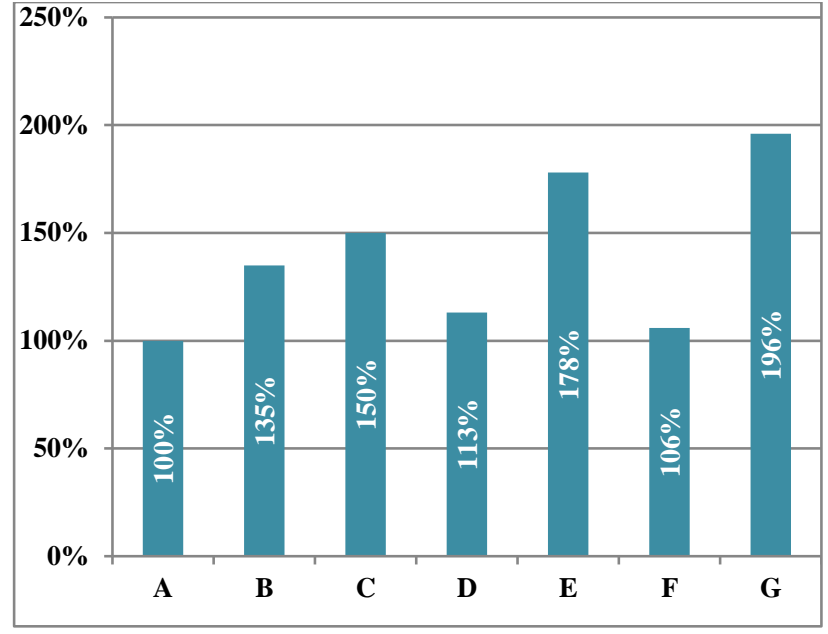

The calculations are based on a single daily dosing pattern. The figures are rounded off to the nearest number for simplicity. The percent cost of the cheapest brand is considered 100 .

Figure 2: Comparison of the cost, in percentage, of seven different brand preparations of Rosuvastatin ten milligram, for a single patient.

\section{DISCUSSION}

Management of certain chronic non communicable diseases, such as ischemic heart disease, stroke, in Indian patients includes hypolipidemic drugs, along with other indicated drugs such as antiplatelet drugs. When the drug treatment is deemed necessary, the statins are one of the important drugs available. In turn These drugs are available in certain specific doses, combinations etc. Amongst the statins, Atorvastatin is the most commonly prescribed drug in India, followed by Rosuvastatin. Profit margin of pharmaceutical companies is extremely variable, often ranging widely. In 1995, the first Drug Price Control Order (DPCO-1995) was published. ${ }^{5}$ For the benefit of patients, government authorize NPPA to regulate prices of medicines which are included in the National List of Essential Medicines (NLEM). Government is making every effort for ensuring availability and affordability of medicines for all the dwellers in India. The order authorized the NPPA to regulate the medicine prices of not only NLEM but also medicines which are not included in NLEM (nonNLEM) ${ }^{6}$ But even after these efforts there is a great price disparity and some drug brand preparations still cost much more than the other brands. In essence every pharmaceutical company strives to quote its own price of the medicines they manufacture without hampering their profit. $^{7}$

In some countries of the world, there are less stringent price control practices. ${ }^{8}$ But in a country like India where drug pricing is of paramount importance, for the sake of population at large there must be some controlling system. This is even more significant in India as there is no welldefined social security system, at the same time medical insurance coverage is very less and most of the healthrelated expenses are to be borne by the consumer or the 
patients themselves. A significant chunk of Indians are becoming financially strained to a serious note, every year due to rising health care costs and a substantial number of patients die at home following discharge against medical advice from the intensive care units due to exuberant cost of the healthcare. ${ }^{9}$

In the present study the yearly cost of Rosuvastatin ten mg for a single patient was considered. It varies between 100 percent to 196 percent between the cheapest and the costliest brands amongst those selected for this study. Thus while prescribing Rosuvastatin ten mg to the patient ,the Pharmacoeconomics of this drug be considered. Prescribing costlier preparations for not so well off patients might create a serious economic strain on the yearly budget of many patients, especially in a country like India. Thus it might be stated that every prescribing practitioner should learn the basic pharmaco economics of drugs, especially for chronic conditions like, ischemic heart disease, stroke, where drug treatment might be required for years together, and mostly for life. In such conditions polypharmacy, which includes prescribing of nine or more drugs to a single patient at any time point, is quite common which might include other drugs such as antihypertensives, antidiabetics, antiplatelet agents as per the merit of the case. ${ }^{10}$ This is a major factor which should compel the prescribing practitioner even further to consider cost benefit of the drugs being used.

\section{CONCLUSION}

Large number of brands of Rosuvastatin ten $\mathrm{mg}$ are available in the market. Pricing of medicines is one of the deciding factors and it has direct financial repercussions on patients resulting into problematic compliance to treatment. Beside price control it is also very necessary to monitor manufacturing of drug under GMP (good manufacturing practice) to ensure quality of medicine. It is the ethical responsibility of all medical professionals that cost effectiveness of drugs should be evaluated before prescribing it to any patients.

Funding: No funding sources Conflict of interest: None declared

Ethical approval: Not required

\section{REFERENCES}

1. Mamatha K, Vishnu K. Cost variation analysis of various brands of oral hypolipidemic drugs available in Indian pharmaceutical market. Int J Res Pharmacol Pharmacotherapeut. 2017;6(3):381-88.

2. Menon A, Kotwal N, Singh Y, Girish R. Statins: Choleaterol guidelines and Indian perspective. Indian J Endocrinol Metabol. 2015;19(5):546-53.

3. Istvan ES, Deisenhofer J. Structural mechanism for statin inhibition of HMG-CoA reductase. Science. 2001;292(5519):1160-4.

4. DPCO, Drug Price Control Order 2013 - National Pharmaceutical Pricing Authority; 2013. Available at: http://www.arthapedia.in

5. Harvard School of Public Health, Boston, MA, USA. How Effective Is India's Drug Price Control Regime? 2007. Available at: https://cdn1.sph.harvard.edu/wpcontent/uploads/sites/114/2012/10/RP256.pdf.

6. Sahay A, Jaikumar S. Does pharmaceutical price regulation result in greater access to essential medicines? Study of the impact of drug price control order on sales volume of drugs in India. 2014;34(4):64-65.

7. DPCO Impact: Pharma cos growth suffers for drugs under price ceiling/ Business Standard News, 2013. Available at: https://www.businessstandard.com/article/companies/dpco-impactpharma-cos-growth-suffers-for-drugs-under-priceceiling-113081800677_1.html.

8. Vernon JA, Golec JH, Hughen WK. The economics of pharmaceutical price regulation and importation: refocusing the debate. Am J Law Med. 2006;32(23):175-92.

9. Balarajan Y, Selvaraj S, Subramanian SV. Health care and equity in India. Lancet. 2011;377(9764):505-15.

10. Kojima G, Bell C, Masaki K. Reducing cost by reducing polypharmacy: The polypharmacy Outcomes project. J Am Med Directors Asso. 2012;13(9):818.e11-e17.

Cite this article as: Rajadnya VA, Dhavalshankh AG. Cost comparisons of seven leading brands of the Hypolipidemic drug, Rosuvastatin available in an India city. Int J Basic Clin Pharmacol 2019;8:1514-7. 